\title{
The effect of topic importance and attitude similarity-dissimilarity on attraction in a multistranger design'
}

DONN BYRNE AND DON NELSON

UNIVERSITY OF TEXAS

\begin{abstract}
In a previous investigation, Ss' attraction toward a stranger who expressed attitudes similar to or dissimilar from their own was found to be a function of similarity-dissimilarity but unrelated to the importance of the attitudinal topics. In the present investigation, a multistranger design was employed in that each of 40 Ss responded to four strangers who expressed similar or dissimilar attitudes about topics of differential importance. Proportion of similar attitudes was again found to have a highly significant effect on attraction while the effects of topic importance, order of presentation, and each interaction were not statistically significant.
\end{abstract}

\section{Problem}

It is often assumed that topic importance is a crucial parameter in the relationship between attitude similarity-dissimilarity and attraction.Newcomb (1956, p. 578) proposes that "The discovery of agreement between oneself and a new acquaintance regarding some matter of only casual interest will probably be less rewarding than the discovery of agreement concerning one's own pet prejudices." Consequently, Newcomb's (1961) index of agreement between two individuals is restricted to topics of importance to both. Presumably, agreement or disagreement concerning unimportant issues would have little or no effect on attraction.

As a test of this proposition, Byrne \& Nelson (1964) scaled 56 attitude items with respect to importance with a group of 138 undergraduates. Then, the items were divided into four 14-item attitude scales which differed in topic importance. A new sample of $112 \mathrm{Ss}$ was obtained, and each $\mathrm{S}$ took one of the four attitude scales. At a later time, the Ss were asked to evaluate a stranger who expressed either similar or dissimilar attitudes with respect to their own on the 14 items. Proportion of similar attitudes was found to have a significant effect on attraction while neither topic importance nor the interaction yielded significant effects.

It was suggested that an adaptation effect may have prevented the importance variable from influencing attraction responses. Since each S took only one of the four attitude scales and responded to only one stranger, he could respond only on the basis of the information at hand. If $\mathrm{S}$ were exposed to the total array of levels of importance and to an array of strangers some of whom had responded with respect to important and some to unimportant topics, it was proposed that topic importance would be much more likely to yield a demonstrable effect. Specifically, it was hypothesized that in a multistranger design, attitude similaritydissimilarity would interact with topic importance in influencing attraction. As topic importance increases, the magnitude of the difference in attraction toward a similar and dissimilar stranger should also increase. Method

As in the previous investigation (Byrne \& Nelson, 1964), the four 14-item attitude scales, representing four levels of topic importance, were employed. Each topic was presented as a six-point scale. The most important topics included belief in God, integration in public schools, birth control, war as a solution to world problems, and divorce. The next most important topics included undergraduate marriages, the university grading system, welfare legislation, a state income tax, and strict disciplining of children. The third level of importance included a Catholic president, the social aspects of college life, political parties, freshmen having cars on campus, and the value of fresh air and exercise. The least important topics included western movies and television programs, classical music, the custom of tipping, gardening, and modern art.

Each of 40 undergraduates (25 males, 15 females) filled out all four of these attitude scales. Several weeks later the Ss were requested to take part in an "interpersonal judgment" experiment. They were told that other students had taken the same series of attitude scales which they had been given earlier in the semester. The Ss were to examine four of these other scales (each filled out by a different fellow student) and make a series of judgments about each of these four anonymous strangers. The judgments included estimates of the person's intelligence, knowledge of current events, morality, adjustment, and two sevenpoint attraction scales. Responses to the last two items are added together to yield a single measure of the dependent variable (Byrne \& Nelson, 1965).

The stranger's scales were actually bogus ones filled out by $\mathrm{E}$ in such a way that $20 \mathrm{Ss}$ responded to strangers who agreed with them on each topic (in terms of being on the same side of the neutral point) and $20 \mathrm{Ss}$ responded to strangers dissimilar on each topic (on the opposite side of the neutral point). The four scales given to each $\mathrm{S}$ were made to appear as if filled out 
TABLE I

Means and Standard Deviations of Attraction Scores for Two Levels of Attitude Similarity and Four Levels of Topic Importance

\begin{tabular}{lrrrrrrrrr} 
Proportion & \multicolumn{8}{c}{ Topic Importance } \\
of Similar & Least & Next Least & Next Most & \multicolumn{2}{c}{ Most } \\
\cline { 2 - 8 } Attitudes & $M$ & SD & $M$ & SD & $M$ & SD & $M$ & SD \\
\hline 1.00 & 10.25 & 2.66 & 9.80 & 2.20 & 10.20 & 2.25 & 10.85 & 2.03 \\
.00 & 5.95 & 2.20 & 6.10 & 2.45 & 7.45 & 2.66 & 6.05 & 2.18 \\
\hline
\end{tabular}

by four different individuals by means of using different colors of ink, various pencils, different styles of checkmarks, etc.

Each $S$ thus responded to four strangers who were either similar or dissimilar to himself in attitudes, on topics representing four levels of importance, with order of presentation systematically varied across subjects.

\section{Results}

The means and standard deviations of the attraction scores (possible range: 2-14) are shown in Table 1 for the topic importance and attitude similaritydissimilarity variables. In an analysis of variance, the only significant effect was that of attitude similarity $(F=93.10, d f=1 / 32, p<.001)$. None of the other effects (topic importance, order of presentation, the double and triple interactions) approached statistical significance.

\section{Diseussion}

Given the findings of this and the previously reported investigation of topic importance, it appears that the effect of attitude similarity-dissimilarity on attraction is not influenced by the importance of the attit dinal topics. Thus, the expression of similar attitudes elicits a positive response and the expression of dissimilar attitudes elicits a negative response whether the topic is as trivial as feelings about gardening or as important as whether or not there is a God.

It should be noted that similarity-dissimilarity on a quite different kind of topic, evaluation of the subject himself, has been found to exert a greater effect on attraction than does similarity-dissimilarity on the sort of impersonal topics utilized here (Byrne \& Rhamey, in press). Nevertheless, within a relatively wide range, topic importance is a negligible factor in determining attraction.

\section{References}

Byrne, D., \& Nelson, D. Attraction as a function of attitude similarity-dissimilarity: the effect of topic importance. Psychon. Sci., 1964, 1, 93-94.

Byrne, D., \& Nelson, D. Attraction as a linear function of proportion of positive reinforcements. J. pers. soc. Psychol., 1965, $1,659-663$.

Byrne, D., \& Rhamey, R. Magnitude of positive and negative reinforcements as a determinant of attraction. J. pers. soc. Psychol., in press.

Newcomb, T. M. The prediction of interpersonal attraction. Amer. Psychologist, 1956, 11, 575-586.

Newcomb, T. M. The acquaintance process. New York: Holt, Rinehart, and Winston, 1961.

Note

1. This research was supported by Research Grant MH-11178-01 from the National Institute of Mental Health, United States Public Health Service.
Continued from page 446 .

similarities in the mediation processes of different organisms, an argument could be made for the advantage of pursuing the study of mediation by utilizing a situation (e.g., the RS-EDS comparison) which provides a basis for systematically relating hypothesized differences in mediation to known differences in discriminative behavior.

And finally, if we may conclude with a comment on a comment, we were entranced by a statement Eimas made based on the IDS-EDS comparison. Citing data obtained with this comparison, Eimas concluded that, ". . all organisms mediate and their ability to do so is not related to either their phylo- or ontogenetic status." This proposition has a breathtaking novelty and we would like to see it elaborated with evidence and implications.

\section{References}

Eimas, P. D. Comment: Comparisons of reversal and nonreversal shifts. Psychon. Sci., 1965, 3,

Kelleher, R. I. Discrimination learning as a function of reversal and nonreversal shifts. J. exp. Psychol., 1956, 51, 379-384.

Kendler, T. S., \& Kendler, H. H. Reversal and nonreversal shifts in kindergarten children. J. exp. Psychol., 1959, 58, 56-60.

Tighe, L. S. The effect of perceptual pretraining on reversal and nonreversal shifts. J. exp. Psychol., 1965, in press.

Tighe, L. S., \& Tighe, T. J. Overtraining and discrimination shift behavior in children. Psychon. Sci., 1965, 2, 365-366.

Tighe, T. J. Effect of overtraining on reversal and extradimensional shifts. J. exp. Psychol., 1965, 70, 13-17.

Tighe, T. J., Brown, P. L., \& Youngs, E. A. The effect of overtraining on the shift behavior of albino rats. Psychon. Sci., $1965,2,141-142$.

\section{Note}

1. This note was prepared during a period of support by grant GB 1673 from the National Science Foundation.

For Comment by Eimas see page 245. 